\title{
Bone mineral density (BMD) and computer tomographic measurements of the equine proximal phalanx in correlation with breaking strength
}

\author{
P. Tóth ${ }^{1}$, C. Horváth ${ }^{2}$, V. Ferencz ${ }^{2}$, B. Tóth ${ }^{3}$, A. Váradi ${ }^{4}$, O. Szenci ${ }^{1}$, G. Bodó ${ }^{5}$ \\ ${ }^{1}$ Clinic for Large Animals, Faculty of Veterinary Science, Szent István University, \\ 2225 Üllö, Dóra major, Hungary \\ ${ }^{2}$ First Department of Medicine, Semmelweis University of Medicine, Budapest, Hungary \\ ${ }^{3}$ Department of Veterinary Clinical Sciences, Purdue University, West Lafayette, IN, USA \\ ${ }^{4}$ Faculty of Veterinary Science, Szent István University, Budapest, Hungary, senior student \\ ${ }^{5}$ University of Bern, Department of Clinical Veterinary Science, Equine Clinic, Switzerland
}

\begin{abstract}
Despite the fact that bone mineral density (BMD) is an important fracture risk predictor in human medicine, studies in equine orthopedic research are still lacking. We hypothesized that BMD correlates with bone failure and fatigue fractures of this bone. Thus, the objectives of this study were to measure the structural and mechanical properties of the proximal phalanx with dual energy X-ray absorptiometry (DXA), to correlate the data obtained from DXA and computer tomography (CT) measurements to those obtained by loading pressure examination and to establish representative region of interest (ROI) for in vitro BMD measurements of the equine proximal phalanx for predicting bone failure force.

DXA was used to measure the whole bone BMD and additional three ROI sites in 14 equine proximal phalanges. Following evaluation of the bone density, whole bone, cortical width and area in the mid-diaphyseal plane were measured on CT images. Bones were broken using a manually controlled universal bone crusher to measure bone failure force and reevaluated for the site of fractures on follow-up CT images. Compressive load was applied at a constant displacement rate of $2 \mathrm{~mm} / \mathrm{min}$ until failure, defined as the first clear drop in the load measurement.

The lowest BMD was measured at the trabecular region (mean \pm SD: $1.52 \pm 0.12 \mathrm{~g} / \mathrm{cm}^{2}$; median: $1.48 \mathrm{~g} / \mathrm{cm}^{2}$; range: $1.38-1.83 \mathrm{~g} / \mathrm{cm}^{2}$ ). There was a significant positive linear correlation between trabelcular BMD and the breaking strength $(\mathrm{P}=0.023, \mathrm{r}=0.62)$. The trabecular region of the proximal phalanx appears to be the only significant indicator of failure of strength in vitro. This finding should be reassessed to further reveal the prognostic value of trabecular BMD in an in vivo fracture risk model.
\end{abstract}

Key words: bone mineral density, DXA, CT, breaking strength, first phalanx, horse

Correspondence to: P. Tóth, email: Toth.Peter@aotk.szie.hu, tel.: +36 306070537 


\section{Introduction}

Stress fractures are considered as one of the most significant causes of economic losses in race horse industry. According to large retrospective studies, $80 \%$ of musculoskeletal injuries in the US (Johnson et al. 1994) and 60\% in the UK (Vaughan et al. 1975) are fatal in racehorses. Fractures of the proximal phalanx are one of the most common incidences during training (Vaughan et al. 1975) and during the daily fracture repair at equine clinics as well (Smith 2010). The most severe longitudinal and comminuted fractures are also observed in the first phalanx (Rooney 1969). Most fractures appear "spontaneous" despite that they are the summation of complex processes with numerous factors involved (Baxter and Turner 2002).

The density of bony structures correlate to skeletal strength and stiffness, which can be estimated by DXA (dual energy X-ray absorptiometry) in people (Genant et al. 1994, Genant et al. 1996, Grier et al. 1996). Further, as a quantitative method, DXA also has the ability to reveal and monitor changes in bone structural properties in humans and in various in vivo animal models (Griffin et al. 1993, Turner et al. 1995, Grier et al. 1996). Previous research in horses focused on the structural and mechanical properties of the third metacarpal bone (Bynum et al. 1971, El Shorafa et al. 1979, Nunamaker et al. 1989) and the proximal sesamoid bones (Young et al. 1991), although little is known about the biomechanical properties of the first phalanx (Thompson et al. 1996, Dzierzęcka and Charuta 2012).

Thus, the objectives of this study were to correlate the data obtained from DXA and CT (computer tomography) measurements to those obtained by loading pressure examination. Further, this experiment aimed to establish representative ROI (region of interest) of the equine proximal phalanx for predicting bone failure force. We hypothesized that bone failure force correlates to bone mineral density (whole bone; medial, lateral and trabecular region) and to the morphometric parameters of the proximal phalanx (cortical width, cortical area, total bone width).

\section{Materials and Methods}

\section{Samples}

Proximal phalanges of the frontlimbs were involved in the study. The horses were euthanised unrelated to muscolosceletal injuries at Szent István University, Faculty of Veterinary Science, Clinic for
Large Animals, Üllö, Hungary. After dissection and manual removal of all soft tissue, the bones were stored in ethyl-alcohol at room temperature until measurements as previously validated (Beaupied et al. 2006). The horses were: $5 \pm 3$ years old (mean \pm SD, median: 5.29 years). There were 4 Lipizzaners, 1 Hungarian half-blood, 1 Hungarian sporthorse, 1 Arabian. Gender distribution was the following: 5 mares, 1 stallion and 1 gelding. Horses were used for either pleasure $(n=3.42 \%)$, carriage-driving $(n=2.29 \%)$ or breeding $(n=2.29 \%)$ purposes.

\section{Bone mineral density (BMD) measurement}

Bones were examined post mortem with a densitometer (Norland XR-26a) at the First Department of Medicine, Semmelweis University of Medicine, Budapest, Hungary. Imitation of soft tissue around the bone was required for the software algorithm used to measure the BMD. Therefore, a $20 \mathrm{~mm}$ plexiglass was used as a substitution for soft tissue as described in detail elsewhere (Tóth et al. 2010). Bones were measured once from dorsopalmar direction (Tóth et al. 2010). As the first step, the BMD of the whole bone was measured followed by selection of three $1 \mathrm{x} 1$ $\mathrm{cm}$ ROIs. The ROIs were the entire bone; the medial cortex (CM), the lateral cortex (CL) at the level of the horizontal axis of the mid-third of the bones and the trabecular region of the sagittal plane of the proximal third, $3 \mathrm{~mm}$ under the level of the deepest point of the metacarpophalangeal joint surface of the proximal phalanges (T) as shown in Fig. 1.

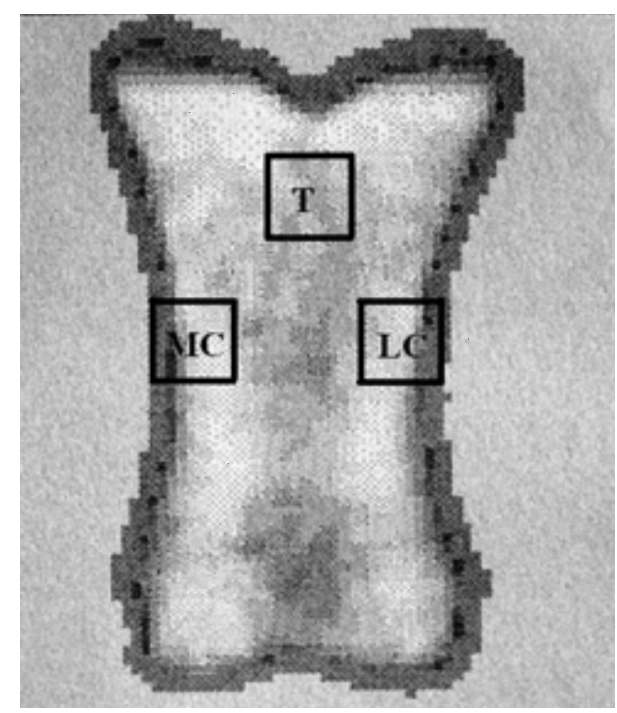

Fig. 1. DXA image of a proximal phalanx from dorsopalmar direction. Region of interests (ROIs) of the first phalanx. $\mathrm{T}$ : trabecular or cancellous bone, MC: medial cortex, LC: lateral cortex. 


\section{Computer tomographic (CT) measurements}

Bones were scanned with a commercially available computer tomography unit (Siemens Somaton Emotion 6 Multislice $\mathrm{CT}^{\mathrm{b}}$ ) using the following settings: 130 kV, 20 mAs, slides: 2 mm; at Kaposvár University, Institute of Diagnostic Imaging and Radiation Oncology, Kaposvár, Hungary. Morphometric parameters of the proximal phalanx were taken at mid-diaphyseal plane using a Siemens SIENET ${ }^{\mathrm{b}}$ software. Cortex width was measured from dorsal, lateral, medial and palmar sides, then the bone total width in either dorsopalmar and lateromedial directions (Fig. 2). Cortical area was calculated from these data using an equation described by Sherman et al (1995). CT images were repeated after loading test to reveal the fracture sites.

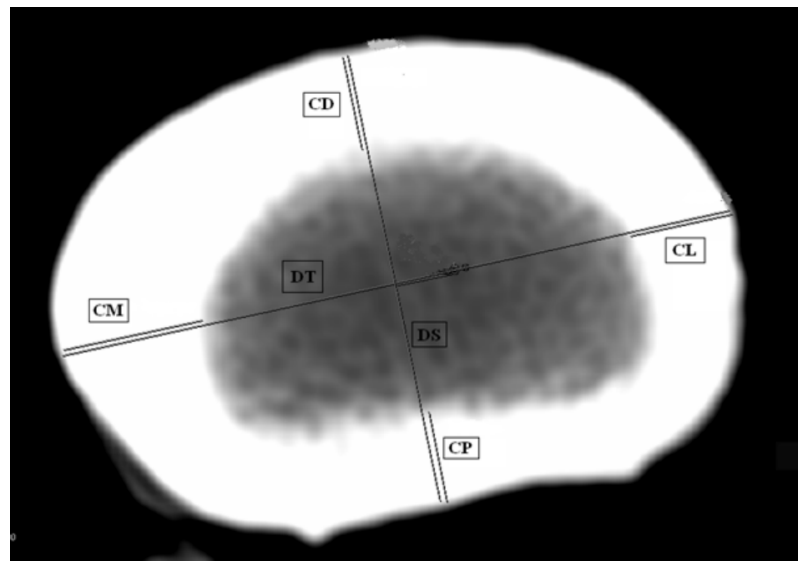

Fig. 2. Transverse CT image at the level of the mid-diaphyseal region of a proximal phalanx. DT: diameter transversa; DS: diameter saggittalis; CM: cortex palmaris; CL: cortex lateralis; CD: cortex dorsalis; CM: cortex medialis.

\section{Loading test}

Biomechanical properties of proximal phalanges were assessed at Budapest University of Technology and Economics, Laboratory of Biomechanical Research. For loading pressure examination a universal bone crusher (ZD-20c universal testing machine) was used. Due to the lack of previous ex vivo data regarding the first phalanx's breaking force measurements, the machine was arbitrarly set for human lumbar spinal preset due to the similar cuboid shape. In order to position the bone properly during measurements, the proximal and distal articular rimms of the P1 bones were removed at the level of the deepest point of the metacarpophalangeal (proximal) and proximal inter- phalangeal joint (distal) articular surfaces of the proximal phalanges by a bandsaw (Fig. 3). The bones were subjected to loading pressure from a proximodistal direction, due to the convex shape of the latero-medial site, which would have prevented accurate pressure loading. Bone failure strength was calculated from loading pressure values.

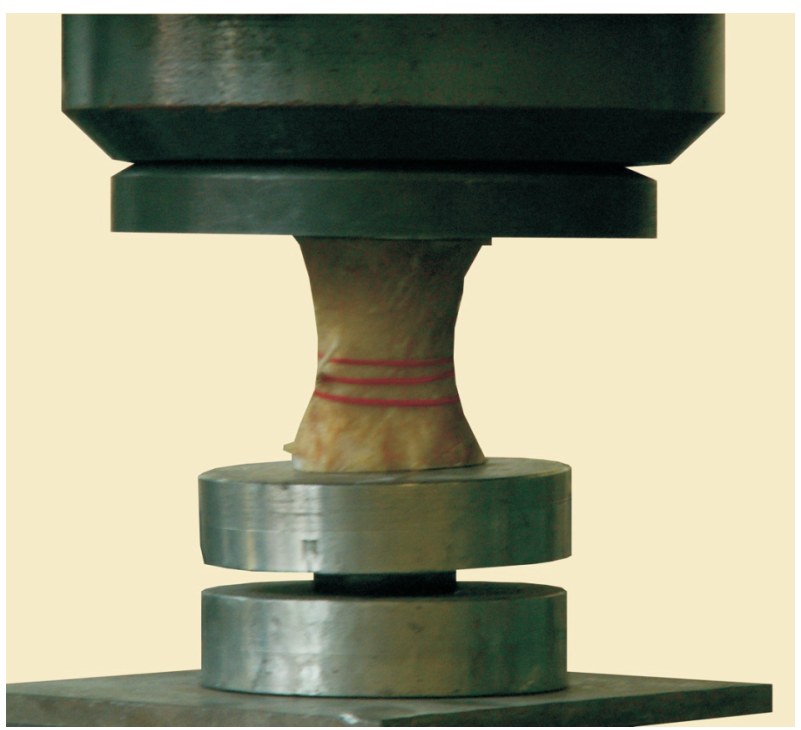

Fig. 3. ZD-20 universal testing machine. The bones were subjected to loading pressure from a proximodistal direction. The proximal and distal articular rimms of the P1 bones were removed at the level of the deepest point of the metacarpophalangeal (proximal) and proximal interphalangeal joint (distal) articular surfaces of the proximal phalanges by a bandsaw.

\section{Statistical Analysis}

Statistical analysis of the data was performed with a commercially available program (Minitab $16^{\mathrm{d}}$ ). Mean, standard deviation, median and range were calculated for bone mineral density, cortical area, cortex width, bone width, loading pressure, and breaking force. Distribution of the data was assesed with the Shapiro-Wilk test. Pearson's linear correlation was used to reveal any association between bone mineral density values (whole bone BMD, traecular BMD, lateral cortical BMD, medial, cortical BMD), cortical area, cortical width (lateral, medial, dorsal, and palmar regions), bone width (saggittal, transversal) and bone breaking strength and loading pressure. Statistical significance was set at $\mathrm{P} \ll 0.05$ and an adequate linear correlation was assumed if regression coefficient was greater than $0.6(r>0.6)$. 


\section{Results}

\section{Samples}

14 proximal phalanges from 7 cadavers were used in the study. 1 phalanx was excluded from the statistical evaluation because following loading test examinations the fracture site could not be located on the CT images.

\section{Bone mineral density (BMD) measurement}

Total bone BMD $\left(\mathrm{g} / \mathrm{cm}^{2}\right)$, lateral cortex BMD, medial cortex BMD, trabecular BMD were as shown in Table 1.

Table 1. Descriptive statistical data of the variables measured across the 13 proximal phalanges in this study.

\begin{tabular}{lccccc}
\hline \multicolumn{1}{c}{ Variable } & $\mathrm{N}$ & Mean & SD & Median & Range \\
\hline Whole BMD $\left(\mathrm{g} / \mathrm{cm}^{2}\right)$ & 13 & 1.91 & 0.14 & 1.96 & $1.68-2.13$ \\
\hline CL BMD $\left(\mathrm{g} / \mathrm{cm}^{2}\right)$ & 13 & 2.19 & 0.15 & 2.2 & $1.95-2.51$ \\
\hline CM BMD $\left(\mathrm{g} / \mathrm{cm}^{2}\right)$ & 13 & 2.1 & 0.13 & 2.05 & $1.93-2.35$ \\
\hline T BMD $\left(\mathrm{g} / \mathrm{cm}^{2}\right)$ & 13 & 1.52 & 0.12 & 1.48 & $1.38-1.73$ \\
\hline Compression strength & & & & & \\
(MPa) & 13 & 74 & 15.56 & 72.56 & $49.96-100$ \\
\hline Breaking force $(\mathrm{kN})$ & 13 & 72 & 13.36 & 74 & $45-92$ \\
\hline CM $(\mathrm{cm})$ & 13 & 0.97 & 0.47 & 1.09 & $0.22-1.44$ \\
\hline CL $(\mathrm{cm})$ & 13 & 0.83 & 0.45 & 1 & $0.15-1.34$ \\
\hline CD $(\mathrm{cm})$ & 13 & 0.39 & 0.13 & 0.43 & $0.15-0.59$ \\
\hline CP $(\mathrm{cm})$ & 13 & 0.53 & 0.23 & 0.63 & $0.09-0.8$ \\
\hline DT $(\mathrm{cm})$ & 13 & 4.66 & 0.299 & 4.75 & $4.17-5.18$ \\
\hline DS $(\mathrm{cm})$ & 13 & 2.8 & 0.55 & 2.6 & $2.28-3.78$ \\
\hline Area $(\mathrm{cm})$ & 13 & 5.4 & 1.90 & 6.06 & $2.47-8.1$ \\
\hline
\end{tabular}

BMD - bone mineral density, DT - diameter transversa, DS - diameter saggittalis, CM - cortex palmaris, $\mathrm{CL}$ - cortex lateralis, CD - cortex dorsalis, CM - cortex medialis, $\mathrm{T}$ - trabecular or cancellous bone, $\mathrm{SD}$ - standard deviation).

\section{Computer tomographic morphometric measurements}

Data are summarized in Table 1 as means of three consecutive measurements of each parameter. Fracture lines were identified in the sagittal plane in 13 $(92.86 \%)$ of 14 specimens. In 5 of $13(38.46 \%)$ cases the fracture lines were located in the proximal and mid-third, in 6 of $13(46.15 \%)$ cases the fracture lines were located in the mid and distal-third and in 2 of 13 $(15.38 \%)$ cases fracture lines were located in the mid-third in the sagittal plane.

\section{Loading test}

Values of compression force and failure force are summarized in Table 1.

\section{Correlations}

Significant positive linear correlation was found between trabelcular BMD and the breaking force $(P=0.023, r=0.62)$. Other parameters did not significantly correlate with the breaking force or compression force as shown in Table 2.

Table 2. Pearson's linear correlations.

\begin{tabular}{|c|c|c|c|}
\hline \multirow{2}{*}{$\begin{array}{c}\text { Variable } \\
\text { Whole bone BMD }\left[\mathrm{g} / \mathrm{cm}^{2}\right]\end{array}$} & \multicolumn{2}{|c|}{$\begin{array}{l}\text { Breaking } \\
\text { force }[\mathrm{kN}]\end{array}$} & \multirow{2}{*}{$\begin{array}{c}\text { Compression } \\
\text { strength [MPa] }\end{array}$} \\
\hline & $\mathrm{P}=0.068$ & $\mathrm{n} / \mathrm{a}$ & \\
\hline $\mathrm{CM}$ BMD $\left[\mathrm{g} / \mathrm{cm}^{2}\right]$ & $\mathrm{P}=0.055$ & $\mathrm{n} / \mathrm{a}$ & $\mathrm{P}=0.377 \mathrm{n} / \mathrm{a}$ \\
\hline LC BMD $\left[\mathrm{g} / \mathrm{cm}^{2}\right]$ & $\mathrm{P}=0.479$ & $\mathrm{n} / \mathrm{a}$ & $\mathrm{P}=0.267 \mathrm{n} / \mathrm{a}$ \\
\hline $\mathrm{BMD}\left[\mathrm{g} / \mathrm{cm}^{2}\right]$ & $\mathrm{P}=0.023$ & $\mathrm{r}=0.62$ & $\mathrm{P}=0.514 \mathrm{n} / \mathrm{a}$ \\
\hline $5 \mathrm{n}$ & $\mathrm{P}=0.533$ & $\mathrm{n} / \mathrm{a}$ & $\mathrm{P}=0.746 \mathrm{n} / \mathrm{a}$ \\
\hline 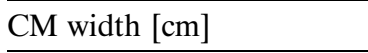 & $\mathrm{P}=0.576$ & $\mathrm{n} / \mathrm{a}$ & $\mathrm{P}=0.921 \mathrm{n} / \mathrm{a}$ \\
\hline & $\mathrm{P}=0.681$ & $\mathrm{n} / \mathrm{a}$ & $\mathrm{P}=0.587 \mathrm{n} / \mathrm{a}$ \\
\hline Writion? & $\mathrm{P}=0.787$ & $\mathrm{n} / \mathrm{a}$ & $\mathrm{P}=0.564 \mathrm{n} / \mathrm{a}$ \\
\hline & $\mathrm{P}=0.482$ & $\mathrm{n} / \mathrm{a}$ & $\mathrm{P}=0.611 \mathrm{n} / \mathrm{a}$ \\
\hline DT $[\mathrm{cm}]$ & $P=0.690$ & $\mathrm{n} / \mathrm{a}$ & $\mathrm{P}=0.1$ \\
\hline Area $\left[\mathrm{cm}^{2}\right]$ & $\mathrm{P}=0.581$ & $\mathrm{n} / \mathrm{a}$ & $\mathrm{P}=0.868 \mathrm{n} / \mathrm{a}$ \\
\hline \multicolumn{4}{|c|}{$\begin{array}{l}\mathrm{r} \text { value is only indicated if } \mathrm{P}<0.05) \text {. } \\
\mathrm{BMD}-\text { bone mineral density, DT - diameter transversa, } \\
\mathrm{DS}-\text { diameter saggittalis, } \mathrm{CM}-\text { cortex palmaris, } \mathrm{CL}-\text { cortex } \\
\text { lateralis, CD - cortex dorsalis, CM - cortex medialis, } \\
\mathrm{T} \text { - trabecular or cancellous bone, } \mathrm{n} / \mathrm{a} \text { - not applicable). }\end{array}$} \\
\hline
\end{tabular}

\section{Discussion}

The lowest BMD was observed in the trabecular ROI. Both the anatomy and physiology of the trabecular region differs from cortical region (Goodship and Smith 2004). It is composed of small trabeculae with a lower mineral content. Unlike the cortical region, the trabecular region is not only under the regulation of vitamin $\mathrm{D}$, calcitonin or parathyroid hormone, but local forces can also induce marked remodeling (Lawrence 2005) enabling this region to respond to mechanical forces directly. Loss of trabecular bone induced by immobilization has been well documented in people (Kazarian and von Gierke 1969) and is characterized by a complete loss or thinning of trabeculae (Ijiri et al. 1995).

This in vitro study revealed a significant positive linear correlation between the trabecular region BMD and failure strength. This result coincides with the cli- 
nical evidence that fracture of the trabecular region is the most common in the proximal phalanx (Nixon 2012). In this study post-fracture $C T$ images revealed that most fracture lines were located in the sagittal plane at the proximal or distal trabecular regions, similarly to an earlier retrospective study (Ellis et al. 1987). Thus, it would be important to focus on this region in further studies, as the trabecular region appears to be the key component in sagittal proximal phalanx fractures. Proximal phalanx fractures are categorized as sagittal or transverse, the latter extends across the bone and does not involve articular surfaces (Ellis et al. 1987). Sagittal proximal phalanx fractures are categorized as incomplete or complete. Although, the most common fracture of the proximal phalanx is the sagittal fracture, breed and usage are important predisposing factors. Fractures of the palmar/plantar processes can occur in Standardbreds (Ruggles 2003), while dorso-frontal fractures can occur both in Standardbreds (Ruggles 2003) and Throroughbreds (Stashak 2002) raced on hard surface. Despite the coinciding results, it must be emphasized that sagittal trabecular fractures are currently attributed to the mechanical effect of the saggital ridge of the third metacarpal bone (Nixon 2012), which was not part of our in vitro model. Davies performed proximodistal loading of equine metacarpal bones with both ends embedded in fibreglass-impregnated resin (Davies 2009), which also did not account for the mechanical load of the proximal articular surface. Since neither Davies' nor our in vitro approaches are exact models of in vivo strains, the relationship between the trabecular region of the proximal phalanx and the sagittal ridge of the metacarpus, and to evaluate the charectiristics and effects of the subchondral bone under the proximal articular surface of the bone warrants further investigation.

During training, microcracks may occur without evidence of lameness and with complete recovery to normal function after a short period of rest (Baxter and Turner 2002). The bone may withstand a particular strain until remodels or, less frequently, the microcracks progress to macroscopic stress fractures (Nunamaker et al. 1990). Light work (compared to regular training load) or immobilization (e.g. longer peroid of stall rest) will decrease BMD in horses, while intense training without transition increases the incidence of bone fractures (Nunamaker et al. 1990). The bone has a dynamic structure and remodels with exercise (Riggs 2002). BMD has been shown to decrease with inactivity or increase with high level of training (Sherman et al. 1995). Due to the insidious nature of stress fractures, there would be a need of an in vitro diagnostic tool that correlates or predicts fracure risk in performance horses. Since our results indicate that there is a significant correlation between failure of strength and trabecular BMD, this hypothesis could be tested in vivo as well.

Correct positioning of the patient/subject is a critical part of the densitometry. DXA machine converts a three-dimensional structure into a two-dimensional image. Elliptical bones may have different BMD value depending on the position of the bone (Rozenberg et al. 1995). In this in vitro experiment bones were measured once from dorsopalmar direction, as described previously (Tóth et al. 2010). Nevertheless, in vivo measurements would require careful limb positioning and deep sedation.

In conclusion, this study suggests that the trabecular region is the sole ROI in predicting failure of strength of the proximal phalanx. In future studies identification of the fracture lines and measurement of the BMD of those particular areas should also be investigated. Further, in vivo experiments are also warranted to reveal whether or not the trabecular BMD data are useful indicator of fracture risk evaluation of the proximal phalanx in horses.

\section{Acknowledgement}

The authors would like to acknowledge the Surgery Department at the Large Animal Clinic, the densitometry laboratory of the First Department of Medicine at the Semmelweis University, the Laboratory of Biomechanical Research of the Budapest University of Technology and Economics and the Institute of Diagnostic Imaging and Radiation Oncology of the Kaposvhr University for contributing to this study with their specialized equipment and expertise.

\section{Abbreviations}

DXA - dual energy x-ray absorptiometry

CT - computer tomograph

BMD - bone mineral density

P1 - proximal phalanx

ROI - region of interest

\section{Manufacturers' adresses}

a - Norland XR-26, Norland Corporation, Fort Atkinson, WI, USA

b - Siemens AG, Erlangen, Germany

c - ZD-20 Universal Testing Machine, Jyoti Ltd, East Germany \& FIB make (India)

d - Minitab Inc., PA, USA 


\section{References}

Baxter GM, Turner AS (2002) Diseases of bone and related structures. In: Stashak TS (ed) Adam's lameness in horses. 5th ed., Philadelphia, Lippincott Williams and Wilkins, pp 401-457.

Beaupied H, Dupuis A, Arlettaz A, Brunet-Imbault B, Bonnet N, Jaffré C, Benhamou CL, Courteix D (2006) The mode of conservation does not affect the architecture and the tensile properties of rat femurs. Biomed Mater Eng 16: 253-259.

Bynum D Jr, Ledbetter WB, Boyd CL, Ray DR (1971) Flexural properties of equine metacarpus. J Biomed Mater Res 5: 63-79.

Carter DR, Hayes WC (1977) The compressive behavior of bone as a two-phase porous structure. J Bone Joint Surg Am 59: 954-962.

Davies HM (2009) Ex vivo calibration and validation of in vivo equine bone strain measures. Equine Vet $\mathrm{J}$ 41: 225-228.

Dzierzęcka M, Charuta A (2012) Bone minearl density and bone mineral content of the bilateral first phalanges of the thoracic limbs in horses. Pol J Vet Sci 15: 159-161.

El Shorafa WM, Feaster JP, Ott EA (1979) Horse metacarpal bone: age, ash content, cortical area and failure stress interrelationships. J Anim Sci 49: 979- 982.

Ellis DR, Simpson DJ, Greenwood RE, Crowhurst JS (1987) Observations and management of fractures of the proximal phalanx on young thoroughbreds. Equine Vet $\mathbf{J}$ 19: 43-49.

Genant HK, Grampp S, Gluer CC, Faulkner KG, Jergas M, Engelke K, Hagiwara S, Van Kuijk C (1994) Universal standardization for dual $\mathrm{x}$-ray absorptiometry: patient and phantom cross-calibration results. J Bone Miner Res 9: 1503-1514.

Genant HK, Engelke K, Fuerst T, Gluer CC, Grampp S, Harris ST, Jergas M, Lang T, Lu Y, Majumdar S, Mathur A, Takada M (1996) Noninvasive assessment of bone mineral and structure: state of the art. J Bone Miner Res 11: 707-730.

Goodship AE, Smith RK (2004) Skeletal physiology: Responsive to exercise and training. In: Hinchcliff $\mathrm{KW}$, Kaneps AJ, Geor RJ (eds) Equine sports medicine and surgery. 1st ed., Philadelphia, Saunders, pp 111-129.

Grier SJ, Turner AS, Alvis MR (1996) The use of dual-energy $\mathrm{x}$-ray absorptiometry in animals. Invest Radiol 31: $50-62$.

Griffin MG, Kimble R, Hopfer W, Pacifici R (1993) Dual-energy $\mathrm{x}$-ray absorptiometry of the rat: accuracy, precision, and measurement of bone loss. J Bone Miner Res 8: 795-800.

Ijiri K, Jee WS, Ma YF, Yuan Z (1995) Remobilization partially restored the bone mass in the non-growing cancellous bone site following long term immobilization. Bone 17: 213S-217S.

Johnson BJ, Ardans AA, Daft BM (1994) California racehorse postmortem programme: a 4-year overview. Proc Am Ass Equi Pract 40: 167-169.

Kazarian LE, von Gierke HE (1965) Bone loss as a result of immobilization and chelation. Preliminary results in Macaca mulatta. Clin Orthop 65: 67-75.
Lawrence LA (2005) Effects of exercise and training on skeletal development in horses. In: Pagan JD (ed) Advances in equine nutrition. 3rd ed., Nottingham, Nottingham University Press, pp 219-226.

Nixon AJ (2012) Phalanges and the metacarpophalangeal and metatarsophalangeal joints. In: Auer JA, Stick JA (eds) Equine surgery. 4th ed., St. Louis, Saunders Elsevier, pp 1300-1325.

Nunamaker DM, Butterweck DM, Provost MT (1989) Some geometric properties of the third metacarpal bone: a comparison between the thoroughbred and standardbred racehorse. J Biomech 22: 129-134.

Nunamaker DM, Butterweck DM, Provost MT (1990) Fatigue fractures in thoroughbred racehorses: relationships with age, peak bone strain, and training. J Orthop Res 8: 604-611.

Riggs CM (2002) Fractures-a preventable hazard of racing thoroughbreds? Vet J 163: 19-29.

Rooney JR (1969) Biomechanics of lameness in horses. Baltimore, Williams and Wilkins, pp 164-167.

Rozenberg S, Vandromme J, Neve J, Aguilera A, Muregancuro A, Peretz A, Kinthaert J, Ham H (1995) Precision and accuracy of in vivo bone mineral measurement in rats using dual-energy $\mathrm{x}$-ray absorptiometry. Osteoporos Int 5: 47-53.

Ruggles AJ (2003) The proximal and middle phalanges and proximal interphalangeal joint. In: Dyson SJ, Ross MW (eds) Diagnosis ans management of lameness in the horse. 1st ed., St. Louis, Elsevier, pp 343-344.

Sherman KM, Miller GJ, Wronski TJ, Colahan PT, Brown M, Wilson W (1995) The effect of training on equine metacarpal bone breaking strength. Equine Vet $\mathbf{J}$ 27: 135-139.

Smith H (2010) Comparison of fracture incidence, type and the associated pain between working equids in Egypt and horses in a UK based referral hospital. Taws Overseas Travel Grant Project Report, pp. 1-17.

Stashak TS (2002) Fractures of the proximal phalanx. In: Stashak TS (ed) Adam's lameness in horses. 5th ed., Philadelphia, Lippincott Williams and Wilkins, pp 755-764.

Thompson KN, Cheung TK, Putnam M (1996) Computerized bone density analysis of the proximal phalanx of the horse. Equi Pract 18: 26-29.

Tóth P, Horváth C, Ferencz V, Nagy K, Gligor N, Szenci O, Bodó G (2010) Assessment of the mineral density and mineral content of the equine third metacarpal and first phalanx bone by dual energy x-ray absorptiometry. Acta Vet Hung 58: 317-329.

Turner AS, Mallinckrodt CH, Alvis MR, Bryant HU (1995) Dual-energy X-ray absorptiometry in sheep: experiences with in vivo and ex vivo studies. Bone 17: 381S-387S.

Vaughan LC, Mason BJE (1976) A clinico-pathological study of racing accidents in horses. A report of a study on equine fatal accidents on racecourses. Horserace Betting Levy Board, London, United Kingdom, pp 3-88.

Young DR, Nunamaker DM, Markel MD (1991) Quantitative evaluation of the remodeling response of the proximal sesamoid bones training-related stimuli in thoroughbreds. Am J Vet Res 52: 1350-1356. 